\title{
ИМИТАЦИОННОЕ МОДЕЛИРОВАНИЕ ДИФФЕРЕНЦИАЛЬНОЙ ГИДРОМАГНИТНОЙ СЬЕМКИ В СТОХАСТИЧЕСКИХ СРЕДАХ
}

\author{
М. В. Кочетов \\ ОАО Морская арктическая геологоразведочная экспедиция, г. Мурманск \\ Поступила в редакцию 29 апреля 2019 г.
}

\begin{abstract}
Аннотация: рассматривается разрешающая способность градиентометрической съемки в условиях стохастических сред с разным соотношением полезный сигнал/помеха, а так же проблема выбора оптимальной базы наблюдений для выделения полезного сигнала в этих средах. Данная задача решалась путём имитационного моделирования градиентометрии на модели с одним источником полезного сигнала (горизонтальная призма). В качестве источников помех использовались горизонтальные цилиндры с вероятностным распределением их центров, размеров и параметров намагничения.
\end{abstract}

Ключевые слова: дифференциальная гидромагнитная съемка, морская градиентометрия, база наблюдений, имитационное моделирование градиентометри, стохастическая модель.

\section{IMITATION MODELLING OF DIFFERENTIAL HYDROMAGNETIC SURVEY IN STOCHASTIC ENVIRONMENTS}

\begin{abstract}
: the resolution of magnetic gradientometry surveying in stochastic environments with different ratios of signal/noise is considered, as well as the problem of choosing the optimal base of observations for the selection of a useful signal in these environments. This problem was solved by imitation simulating gradientometry on a model with a single source of useful signal (horizontal prism). Horizontal cylinders were used as sources of noise, with the probability distribution of their centers, sizes and magnetization parameters.
\end{abstract}

Keywords: differential hydromagnetic survey, marine gradientometry, observation base, simulation of gradientometry, stochastic model.

\section{Введение}

Морская магниторазведка находит широкое применение в комплексе геофизических исследований акваторий как для решения сугубо геологических задач изучения строения земной коры и её отдельных структурных этажей [1-5], так и при детальных инженерных изысканиях верхней части осадочного разреза $[1,6,7]$.

Как правило, гидромагнитные наблюдения осложняет множество случайных процессов, имеющих разное происхождение. Одним из важнейших природных факторов, который следует учитывать при проведении градиентометрических исследований, это гидродинамическая обстановка района работ. Тут следует отметить специфическую особенность среды, ограничивающей предельную точность измерений. Известно, что движение проводника в магнитном поле (МП) порождает индукционные электрические токи. Подобный механизм действует в морской волне, являющейся своеобразным проводником. Магнитные поля, генерируемые возникающими токами, связаны с амплитудой и периодом морского волнения, которое создаёт некоторый фон помех, вполне ощутимый для современных магнитометров [8, 9]. Помимо шумов естественного происхождения иногда приходится бороться с помехами техногенной или геологической природы. Так при поисках локальных объектов известных размеров, залегающих в определённом интервале глубин, приходится избавляться от затушевывающих полезный сигнал аномалий иного характера.

Выделение полезного сигнала на фоне помех классическая задача в различных приложениях науки и техники [10-12]. При проведении градиентометрии в отдельных районах работ со своими специфическими условиями учесть влияние всех возможных помех на стадии планирования работ и оценить их воздействие на разрешающую способность метода не всегда получается, а в некоторых случаях и попросту невозможно [13-17]. Для решения подобных задач в геофизике широко применяется моделирование.

Важной задачей при постановке градиентометрических исследований является подбор оптимальной базы наблюдений, которая бы позволила выделить аномалии от перспективных неоднородностей и в то 
же время сгладить шумы и помехи. От правильно подобранной базы на стадии планирования работ зависит итоговая точность и детальность съёмки [18-20].

В данной работе решается прямая задача геофизики путём построения модели среды, содержащей как полезный сигнал, так и случайные помехи разной интенсивности. Целью такого моделирования является оценка возможностей использования дифференциальной гидромагнитной съемки в условиях наличия естественных помех. В связи с этим, считается целесообразным рассмотреть различные условия моделируемых сред для выявления разрешающей способности градиентометрии при разном соотношении полезный сигнал/помеха.

\section{Моделирование среды наблюдений с невысоким фоном помех}

Построение физико-математических моделей среды осуществлялось в программе Mathcad 15 [21]. За искомый объект, генерирующий полезную аномалию МП, была выбрана горизонтальная призма с параметрами: высота (h) - 60 метров, ширина (b) - 200 метров, залегающая на глубине 50 метров. С намагниченностью (J) тела - 0,6 A/м и углом наклонения вектора намагничения (i) $-60^{\circ}$. На рис. 1 показано поле от призмы, где BZmod и BXmod - вертикальная и горизонтальная компоненты МП, а $\Delta \mathrm{Bmod}$ модуль вектора индукции.

Для генерации поля случайных помех использовались горизонтальные цилиндры. Местоположение центров цилиндров в плоскости моделирования и их

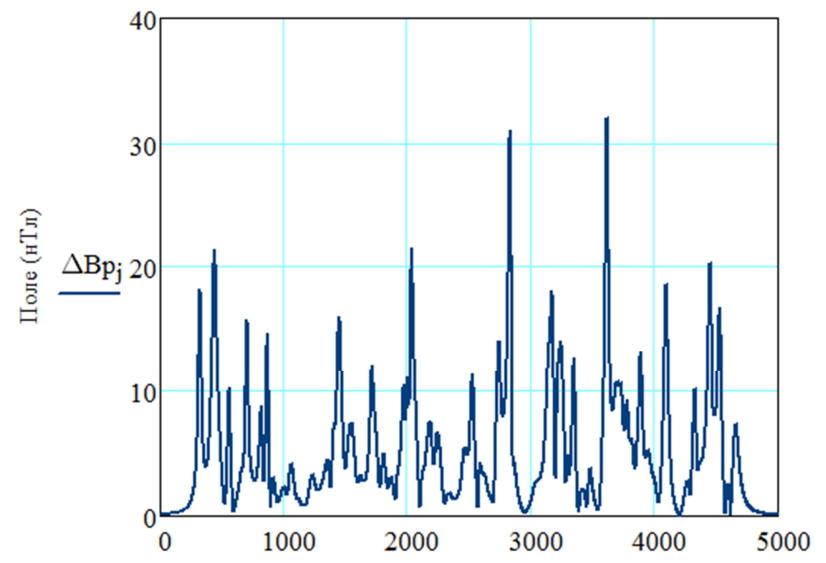

Puc. 2. Магнитное поле помех - случайной последовательности горизонтальных цилиндров (горизонтальная ось - точки по профилю вычислений поля).

В приведённом случае полезный сигнал практически на порядок превышает поле помех. При таком соотношении полезный сигнал/помеха, аномалия от призмы довольно чётко выделяется, а оптимальная база расчета градиента МП составляет 10-20 метров. На рис. 4 показаны посчитанные графики полей горизонтальных градиентов с базами 20 (a) и 40 (б) метров. Градиент высчитывался по значениям модуля

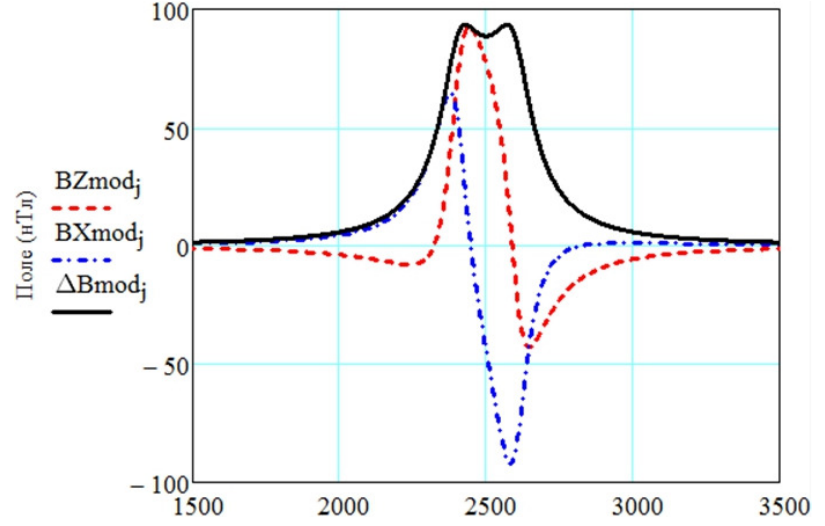

Puc. 1. Магнитное поле призмы (горизонтальная ось точки по профилю вычислений поля).

размеры заданы по равномерному закону распределения. Источники залегают в интервале глубин от 15 до 45 метров и имеют вариации радиусов от 1 до 8 метров. Длина профиля наблюдений 5 км. Значения намагниченностей источников помех распределены по логистическому закону и имеют следующие параметры: математическое ожидание - 0,4 A/м, масштабный коэффициент - 0,02. Массив углов наклонений векторов намагничений цилиндров сгенерирован по нормальному закону распределения. Данный подход к поставленной задаче позволил получить стохастическую модель среды наблюдений. На рис. 2 показан график модуля полного вектора индукции МП цилиндров, а на рис. 3 отображено суммарное поле призмы с помехами.

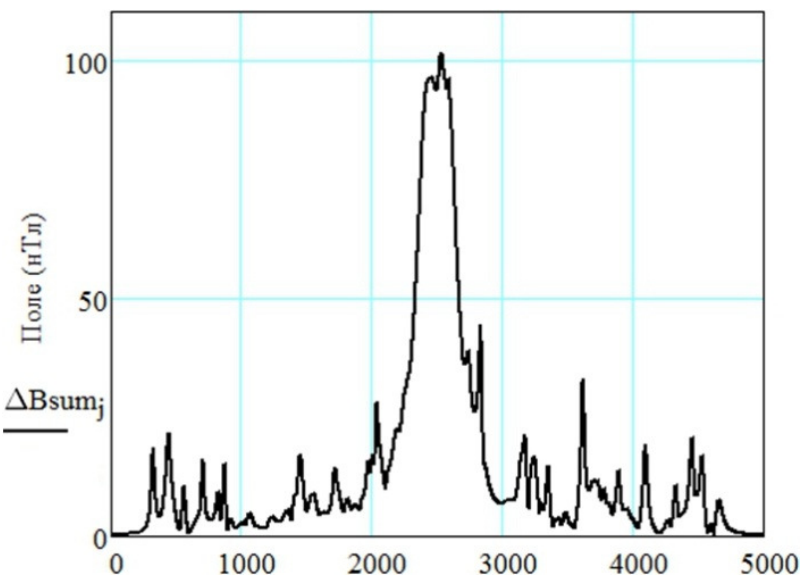

Puc. 3. Суммарное магнитное поле призматического источника и помех (горизонтальная ось - точки по профилю вычислений поля).

вектора магнитной индукции.

На графиках градиента с базами 20 и 40 метров видно, что при увеличении базы наблюдений происходит фильтрация высокочастотной составляющей, которая затушевывает низкочастотный импульс от объекта исследований. Однако при увеличении базы наблюдений с уменьшением интенсивности поля помех происходит и уменьшение амплитуды полез- 
ного сигнала. Причём, двукратное увеличение базы приводит к двукратному уменьшению амплитуды полезного сигнала, что чётко прослеживается на графиках восстановленного магнитного поля по горизонтальному градиенту. На рис. 5 приведены графики восстановленного магнитного поля по горизонтальному градиенту с шагом 20 метров $(a)$ и 40 метров (б).

На графиках восстановленного магнитного поля

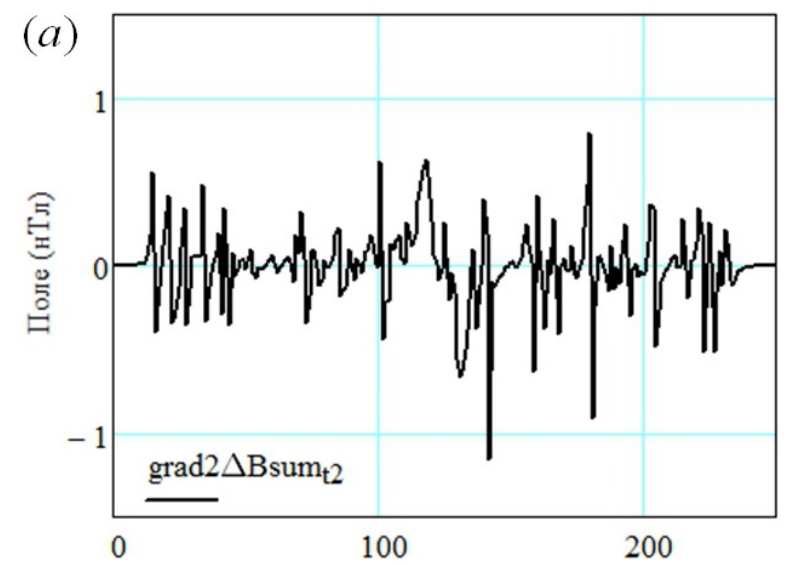

видно, что предельная база наблюдений для данного случая 20 метров. При использовании больших баз наблюдения поле от призмы становится меньше 5 нТл, что на практике входит в погрешность увязки гидромагнитных съёмок с протонными магнитометрами средней точности [22]. Если провести качественное сравнение форм аномалий восстановленного поля для баз 20 и 40 метров, можно увидеть, что общий вид полезного сигнала не изменился.

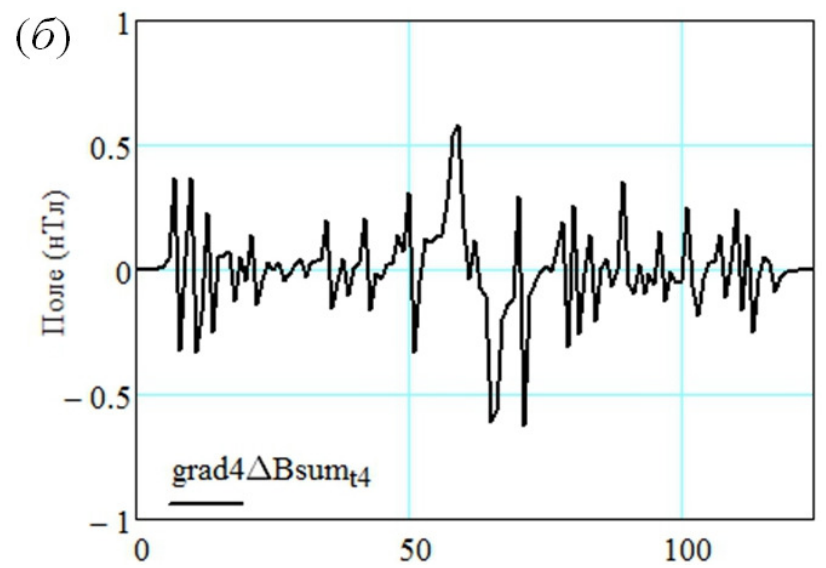

Puc. 4. Графики горизонтальных градиентов с шагом: $a-20$ м, $\sigma-40$ м. Горизонтальные оси на графиках - точки по профилю вычислений поля с шагом, соответственно 20 м и 40 м.
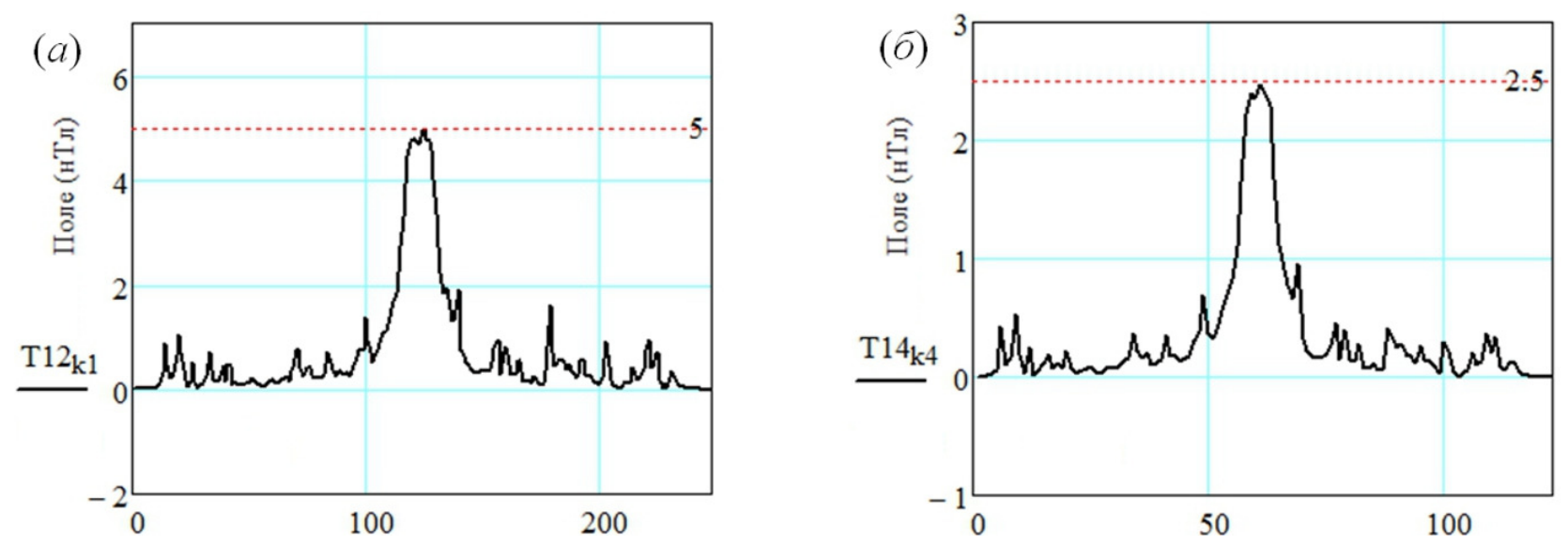

Puc. 5. Графики восстановленного магнитного поля по горизонтальному градиенту с шагом: (а) - 20 м, (б) - 40 м. Горизонтальные оси на графиках - точки по профилю вычислений поля с шагом, соответственно 20 м и 40 м.

Моделирование экстремальной среды наблюдений

Для создания сложных условий съёмки в качестве объектов-помех применялись горизонтальные цилиндры, а за тело, создающее полезный сигнал - призма. Параметры призмы не менялись, и поле источника соответственно осталось прежним (рис. 1). Уровень помех в свою очередь был увеличен в два раза. Для этого были изменены значения намагниченностей цилиндров до 4 A/м, а так же задано максимальное предельное значение радиусов источников поля до 50 м. Массив глубин цилиндров сформирован по логистическому закону распределения с параметрами: математическое ожидание 70 м, масштабный коэффициент 3. Данный подход позволил сфокусировать центры источников в заданном интервале глубин. В ре- зультате была получена «низкочастотная» стохастическая модель поля помех. На рис. 6 показан график модуля вектора индукции МП $(\Delta \mathrm{Bp})$, а на рис. 7 суммарное поле призмы с помехами ( $\Delta$ Bsum).

В приведённой модели амплитуда аномалии превышает уровень помех в два раза. В таких условиях градиентометрией выделить полезный сигнал и в то же время подавить шумы, проблематично. Ситуация обуславливается суперпозицией магнитных полей от источников помех - цилиндров, близких по своим размерам к аномалообразующему объекту - призме. В связи с чем, выделение полезного сигнала на «низкочастотном» фоне, близком к периоду полезного сигнала, затрудняется. База градиента начинает одинаково хорошо выделять как помеху, так и полезный сигнал. 


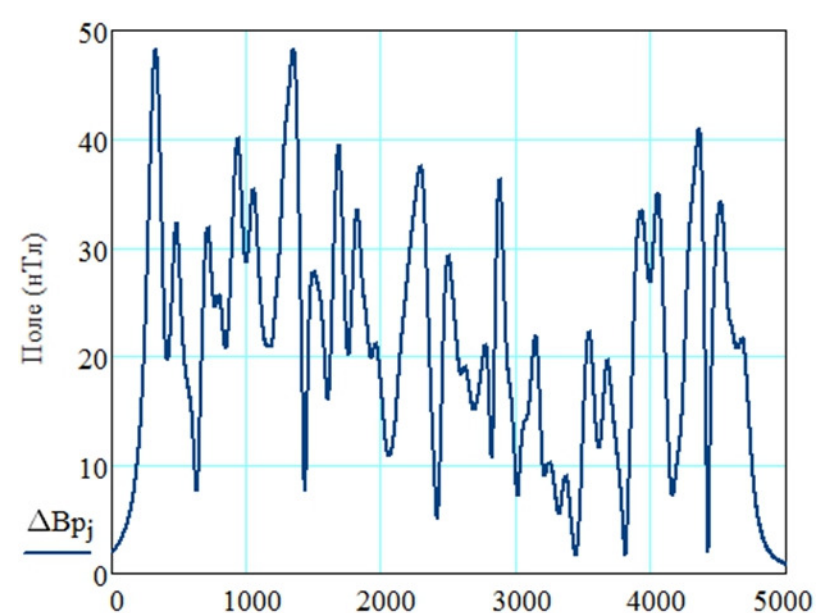

Рис. 6. МП помех - горизонтальных цилиндров (горизонтальная ось - точки по профилю вычислений поля).

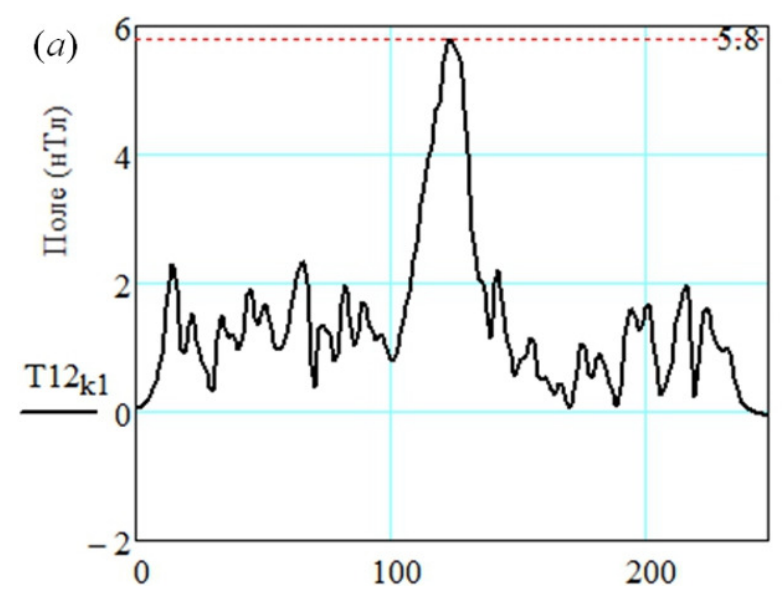

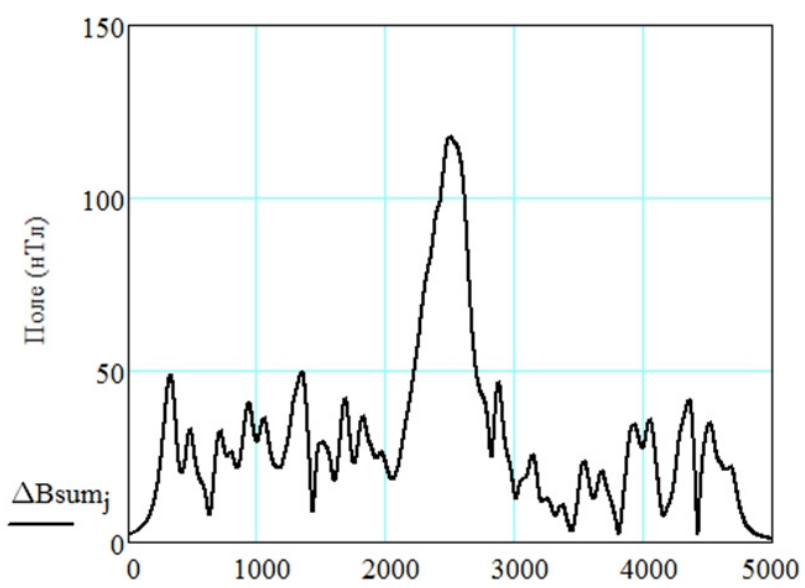

Pис. 7. МП призмы осложнённое помехами (горизонтальная ось - точки по профилю вычислений поля).

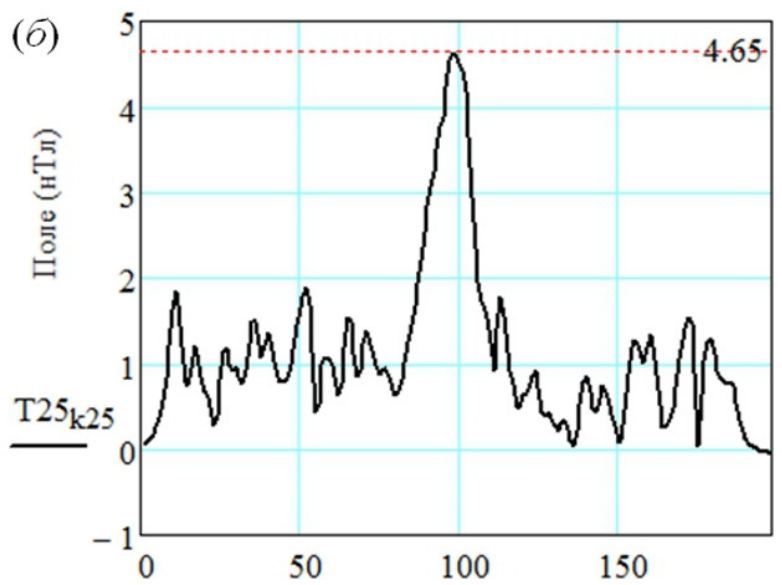

Puc. 8. Графики восстановленного МП по горизонтальному градиенту с шагом $a-20$ м, $\sigma-25$ м. Горизонтальные оси на графиках - точки по профилю вычислений поля с шагом, соответственно 20 м и 25 м.

Для данного случая оптимальная база расчета градиента МП составляет 20-25 метров. Она позволяет немного уменьшить шумы и определить аномалию. На рис. 8 показаны графики восстановленного магнитного поля по горизонтальному градиенту с шагом по профилю 20 (а) и 25 (б) метров. Разница в интенсивности аномалий при их использовании составляет 1,15 нТл.

В свою очередь повысить уровень полезного сигнала при использовании больших баз наблюдений можно методическим путём, для этого следует заглубить измерительную аппаратуру. Сближение приборов с источниками поля реализует более интенсивный сигнал, чем на водной поверхности. Что сказывается на детальности съемок.

Для того, что бы аномалия от локального объекта с градиентометрической базой 25 метров выделилась более ярко, было достаточно перенести поверхность наблюдений на 20 метров вниз. В результате интенсивность от локального объекта немного увеличилась, рис. 9.

Таким образом, при выборе баз наблюдений необходимо учитывать амплитуду аномалий, характер изу- чаемого поля и уровень зашумленности. Так как от этих факторов зависит методика, которую необходимо применять в данном районе работ для получения наибольшей информации об изучаемых объектах среды.

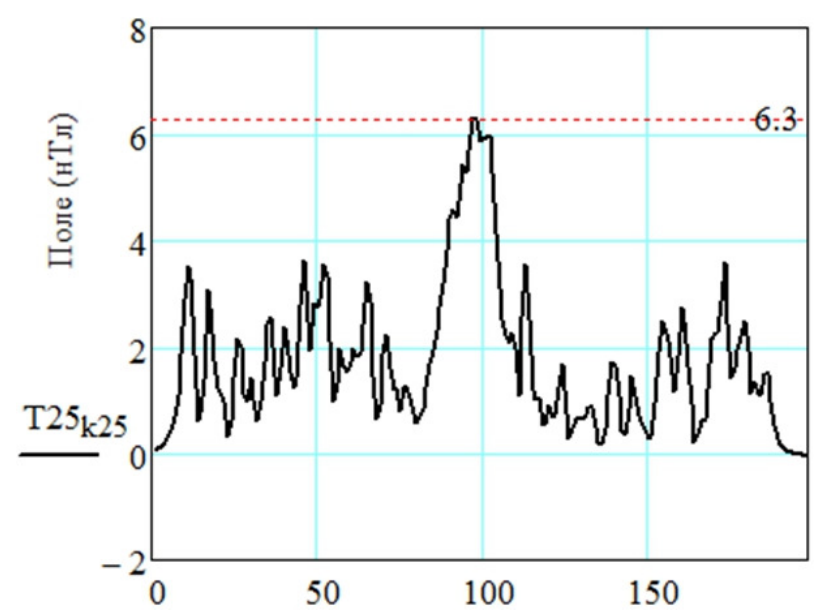

Puc. 9. Восстановленное магнитное поле по горизонтальному градиенту с базой 25 м, вычисленного для глубины $20 \mathrm{M}$. 


\section{Заключение}

В результате моделирования выяснилось, что использование небольших баз наблюдений целесообразно применять при съемках, нацеленных на выделение незначительных магнитных масс с локальными ярко выраженными аномалиями, превышающими уровень помех в 3 раза и больше. Такой подход в данном случае позволит локализовать полезную аномалию и сгладить помехи. Для выделения аномалий от крупных источников поля с завышенным уровнем помех возможно применение больших баз наблюдений. Однако тут важно помнить, что между выделяемым сигналом и величиной базы наблюдений существует обратная зависимость. Двукратное увеличение базы наблюдений приводит к двукратному уменьшению интенсивности аномалий восстановленного магнитного поля по рассчитанному горизонтальному градиенту поля. Поэтому необходимо предусматривать возможное снижение детальности съёмки при работах с большим шагом градиента. Так же важно указать о необходимости заглубления приборов с целью их приближения к аномалии образующим объектам. Такая методика позволяет компенсировать снижение интенсивности полезного сигнала при градиентометрии с большими базами наблюдений и, следовательно, способствует повышению детальности работ.

Когда же амплитуда аномалий становится сопоставима с интенсивностью помех и период помех приближается к ширине полезного сигнала, разрешающая способность метода начинает ограничиваться. База расчёта градиента перестаёт разделять поле помех и поле полезного сигнала.

Таким образом, оператор дифференцирования является фильтром высоких частот [12], что и обеспечивает более высокую разрешающую способность градиентометрических съемок по сравнению с модульными наблюдениями.

Автор выражает благодарность проф. В. Н. Глазневу за постановку задачи исследования и полезное обсуждение результатов данной работы.

\section{ЛИТЕРАТУРА}

1. Инструкция по магниторазведке (наземная магнитная съёмка, аэромагнитная съёмка, гидромагнитная съёмка). - Л.: Недра, 1981. -263 c.

2. Гордин, B. М. Морская магнитометрия / В. М. Гордин, Е. Н. Розе, Б. Д. Углов. - М.: Недра, 1986. - 232 с.

3. Геотрансект Евро-3 / А. В. Чекунов [и др.] // Геофизический журнал, 1993. - Т. 15. - N 2. - С. 3-32.

4. Crustal structure of the Baltic shield along the Pechenga - Kostomuksha - Lovisa geotraverse / F. P. Mitrofanov [et al.] // International Geology Review. - 1998. - V.-40. - №11. - P. 990-997.

5. Complex geological-geophysical 3D model of the crust in the southeastern Fennoscandian Shield: Nature of density layering of the crust and the crust-mantle boundary / V. N. Glaznev [et al.] // Geodynamics \& Tectonophysics. - 2015. - V. 6 (2). - P. 133-170. 6. Семевский, Р. Б. Специальная магнитометрия / Р. Б. Семевский, В. В. Аверкиев, В. А. Яроцкий. - СПб.: Наука, 2002. - 228 с.

ОАО Морская арктическая геологоразведочная экспедиция Кочетов Михаил Владимирович, геофизик комплексной геолого-геофизической партии.E-mail: kochetov.mv@mage.ru
7. Владов, М.Л. Геофизические методы инженерногеологических задач / М. Л. Владов, А. В. Старовойтов. - М.: ГСД Продакшен, 1998. - 67 с.

8. Глазнев, В. Н. Магниторазведка. Электронный учебный курс / В. Н. Глазнев, Т. А. Воронова. - Электронный университет, 2017. - Режим доступа: https://edu.vsu.ru/course/view.php?id=2427.

9. Магниторазведка. Справочник геофизика. / Под ред. В. Е. Никитского, Ю. С. Глебовского. - М.: Недра, 1980. - 367 с. 10. Лукин, А. С. Введение в цифровую обработку сигналов (математические основы). / А. С. Лукин. - М: МГУ, 2002. - 44 с.

11. Глазнев, В.Н. Геофизическая аппаратура. Учебное пособие / В. Н. Глазнев. - Воронеж: ООО ИПЦ «Научная книга», 2019. - 73с. 12. Глазнев, В. Н. Интегральные преобразования в геофизике. Учебное пособие / В.Н. Глазнев. - Воронеж: ООО ИПЦ «Научная книга», 2019. - 45 с.

13. Глазнев, B.Н. Оценка разрешающей способности магниторазведки в сложных полях / В. Н Глазнев, И. И. Берман // Геофизические исследования северо-восточной части Балтийского щита. - Апатиты, изд. КФАН СССР, 1976. - С. 109-114.

14. Глазнев, В.Н. Оценка границ применимости стохастических моделей потенциальных полей / В. Н Глазнев // Вестник Воронеж. гос. ун-та. Сер.: Геология. - 1999. - № 8. - С. 153-156.

15. Глазнев, В. Н. Оценка разрешающей способности магнитного градиентометрического метода при решении инженерных задач / В. Н. Глазнев, В. С. Стариков // Материалы XVI международной конференции «Структура, свойства, динамика и минерагения литосферы Восточно-Европейской платформы». Воронеж: изд. ВГУ, 2010. - С. 183-197.

16. Кочетов, М. В. Стохастическая оценка разрешающей способности дифференциальной гидромагнитной съёмки / М. В. Кочетов, В. С. Стариков // Инновационные методики геофизических исследований: материалы ежегодной молодежной научной конференции кафедры геофизики ВГУ [под ред. А. А. Аузина, О. М. Муравиной]. - Воронеж: Издательскополиграфический центр «Научная книга», 2018. - 111 с.

17. Стариков, В. С. Оценка разрешающей способности гидромагнитной градиентометрической съёмки / В. С. Стариков, М.В.Кочетов // Инновационные методики геофизических исследований: материалы ежегодной молодежной научной конференции кафедры геофизики ВГУ [под ред. А. А. Аузина, О. М. Муравиной]. - Воронеж : Издательско-полиграфический центр «Научная книга», 2018. - 111 с.

18. Кочетов, М. В. Практика в ОАО «Морская Арктическая Геологоразведочная Экспедиция» / М. В. Кочетов // Практика геологов на производстве: сборник трудов Всероссийской студенческой научно-практической конференции - Ростов-на-Дону: Издательство Южного федерального университета, 2016. - С. 150.

19. Кочетов, М. В. Оценка разрешающей способности морской дифференциальной гидромагнитной съёмки / М. В. Кочетов, В. А. Журавлев, В. Н. Глазнев // Материалы VI Международной конференции молодых ученых и специалистов «Новое в геологии и геофизике Арктики, Антарктики и Мирового Океана», посвященная 70-летию основания НИИГА -ВНИИОкеангеология [Отв. ред. А.С. Бич]. - СПб.: ФГБУ «ВНИИОкеангеология», 2018 - C. $45-46$.

20. Кочетов, М. В. Оптимизация методики дифференциальной гидромагнитной съемки / М. В. Кочетов, В. А. Журавлев // Вестник Воронеж. гос. ун-та. Сер.: Геология. -2018. - № 2. - С. 127-131.

21. Кирьянов, Д. В. Mathcad14 / Д. В. Кирьянов. - СПб.: БХВПетербург, 2007. - 704 С.

22. Магниторазведка: метод. Указания [Электронный ресурс] / сост. В. А. Кортунов, В. И. Платунов. - Владивосток: Изд-во ДВГТУ, 2006. - 24 с. - Режим доступа: http://window.edu.ru/ catalog/pdf2txt/131/45131/21909?p_page $=2$.

JSC Marine Arctic Geological Expedition (JSC MAGE), Murmansk. Kochetov M.V., Geophysicist of the complex geological and geophysical party. Tel.: +7 (8152) 450709 